\title{
FORMAÇÃO DE QUADROS INTELECTUAIS ORGÂNICOS NA PSICOLOGIA INDUSTRIAL NOS EUA DO INÍCIO DO SÉCULO XX: ASPECTOS POLÍTICOS, ECONÔMICOS E IDEOLÓGICOS
}

\author{
R. M. VIEIRA ${ }^{1}$, R. K. HIDAKA ${ }^{2}$ \\ Instituto Federal de Educação, Ciência e Tecnologia do Pará ${ }^{1}$ \\ Instituto Federal de Educação, Ciência e Tecnologia de São Paulo ${ }^{2}$ \\ rkhidaka@yahoo.com.br²
}

Artigo submetido 23/10/2019 e aceito 19/11/2019

DOI: 10.15628/holos.2019.9091

\section{RESUMO}

Este trabalho tem como objetivo mostrar como se deu a formação de uma camada de intelectuais orgânicos ligados à Psicologia Industrial no início do século XX e suas respectivas funções econômica e ideológica de classe. Para tanto foram exploradas as principais obras de algumas das figuras que tiveram grande influência no advento da Psicologia Industrial no período em questão, bem como comentadores de suas obras. A ação deste grupo foi analisada a partir de categorias teóricas como classe social, relações sociais de produção e intelectuais orgânicos. Diante da pesquisa feita, foi possível observar como os Psicólogos Industriais e afins tiveram uma importância estratégica na recomposição das forças produtivas do capitalismo industrial estadunidense do início do século XX e cujos desdobramentos teóricoideológicos permanecem influenciando a formação de quadros gestores até hoje.

PALAVRAS-CHAVE: Intelectuais orgânicos, Psicologia Industrial, Forças produtivas, EUA.

\section{FORMATION OF ORGANIC INTELLECTUALS LAYERS IN EARLY 20TH CENTURY ON THE INDUSTRIAL PSYCHOLOGY IN THE USA: POLITICAL, ECONOMIC AND IDEOLOGICAL ASPECTS}

\begin{abstract}
This paper aims to show how the formation of a layer of organic intellectuals linked to Industrial Psychology in the early twentieth century and their respective economic and ideological class functions. Therefore, was analyzed the main works of some of the most important figures that had a great influence on the advent of Industrial Psychology in the period in question, as well as commentators of their works. The action of this group was analyzed from theoretical categories such as social
\end{abstract}

class, social relations of production and organic intellectuals. Given the research done, it was possible to observe how the Industrial Psychologists and its related had a strategic importance in the recomposition of the productive forces of the American industrial capitalism of the beginning of the twentieth century and whose theoretical and ideological developments continue to influence the formation of managerial staff until today.

KEYWORDS: Organic intellectuals, Industrial Psychology, Productive forces, EUA. 


\section{INTRODUÇÃO}

A relação entre corpo mente aparece como objeto de interesse de pensadores desde a Grécia Antiga. No caso de Platão e Aristóteles, por exemplo, as reflexões a respeito da relação corpo/mente podem ser encontradas em formulações sobre a capacidade intelectiva do homem em perceber, sentir, pensar e raciocinar. $O$ ponto central de tais concepções era procurar saber como e de que forma este intelecto nos diferencia dos demais seres viventes e de modo supostamente ele orienta e dá sentido à vida. O corpo, em unidade substancial com a alma, era entendido como o lugar no qual as capacidades mentais encontravam sua forma de expressão (Nussbaum \& Rorty, 1995).

Ainda que presente desde a Antiguidade, são as reflexões sobre a relação entre corpo e mente que emergiram na Inglaterra na segunda metade do século XIX aquelas que, com efeito, impactarão à Psicologia Industrial (PI). Isso porque a PI, enquanto campo de conhecimento, surge na passagem do século XIX para o XX, sendo uma herdeira direta do empirismo inglês e, também, estadunidense. Sua gênese está relacionada ao processo de incorporação e metodologização da Psicologia a partir de técnicas e práticas utilitárias.

No campo de assuntos próximos à Psicologia, o movimento empirista estimulou, dentre outros, os estudos Thomas Willis (1612 - 1675) em torno da anatomia e neurologia e as obras de Descartes (1596-1650), dentre as quais podem ser mencionadas Meditações sobre Princípios de Filosofia (1641), Paixões da Alma (1649) e Tratado sobre o Homem (Hughes, 1991).

Posteriormente, Johann F. Herbart (1776-1841) tentou desenvolver uma base matemática para uma psicologia científica. Embora ele fosse incapaz de conceber empiricamente os termos de sua teoria psicológica, seus esforços fizeram com que cientistas alemães como Ernst Heinrich Weber (1795-1878) e Gustav Theodor Fechner (1801-1887) estabelecessem relações matemáticas entre a grandeza dos estímulos externos e as intensidades das sensações resultantes, criando, a partir disto, a psicofísica (Goodwin, 2005; Stevens, 1986).

Saindo da Grã-Bretenha, em 1874, o alemão Wilhelm Wundt (1832-1920) assumiu uma cátedra em Zurique, ocasião em que publicou seu livro Grundzüge der Physiologischen Psychologie (Princípios de Psicologia Fisiológica). Depois de ter ocupado um cargo de prestígio em Leipzig no ano de 1875, fundou um laboratório especificamente dedicado à pesquisa em psicologia experimental em 1879, reconhecido como o primeiro laboratório especificamente de Psicologia. Em 1883, lançou uma revista na qual passou a publicar os resultados das suas pesquisas e de seus estudantes (Bringmann \& Tweney, 1980). Wundt atraiu um grande número de alunos não só da Alemanha, mas também de outros países (Rieber \& Robinson, 2001). É considerado o maior responsável em reorientar as questões psicológicas da filosofia para uma ciência experimental, mais precisamente a fisiologia, fazendo que, desse modo, inicialmente tais pesquisas ainda estivessem significativamente atreladas à influência da psicofísica. Todas essas práticas e métodos são estimulados pelo avanço técnico em meio ao pragmatismo estimulado pela evolução técnica no contexto inglês. 
A Psicologia, como será demonstrado adiante, foi apropriada para a apropriação nas relações de produção do capitalismo inglês e sobretudo estadunidense e na respectiva composição dos agentes envolvidos. Desse processo nasceu a Psicologia Industrial.

Na década 80 do século XIX, laboratórios de psicologia experimental foram sendo abertos. Entre 1887 e 1888 foram inaugurados seis nos Estados Unidos. Tais marcos sinalizam o caminho para a consolidação da formação de quadros intelectuais, portadores de conteúdos e saberes enunciantes e a institucionalização da Psicologia em terreno estadunidense em meio a valorização do pragmatismo herdado da Inglaterra. Concomitantemente, surgem as primeiras investidas práticas nas relações de produção tendo elementos originários da Psicologia como ferramenta para controle da força de trabalho, bem como o esforço em institucionalizar pesquisas e ações voltadas à incorporação da Psicologia no campo industrial.

Neste texto, procuraremos mostrar como se deu a conformação de quadros intelectuais orgânicos ligados à Psicologia Industrial, destacando sua ação econômica e ideológica no processo histórico daquela que, no século XX, se tornará a sociedade capitalista industrial mais avançada os Estados Unidos da América.

\section{METODOLOGIA}

Nas linhas que seguem, serão mencionados os dados e informações coletados a partir da leitura de obras sobre o advento da PI, seja através da leitura dos primeiros indivíduos que se dedicaram, direta ou indiretamente, a analisar como a Psicologia poderia ser incorporada nas relações sociais de produção no contexto da chamada Administração Científica, seja por meio de comentadores. A autointitulada Administração Científica, por sua vez, é marcada pela recomposição das forças produtivas do capitalismo industrial estadunidense do início do século $X X$. Fato que impulsionou a formação de quadros de técnicos e intelectuais orgânicos com o objetivo de consolidar e institucionalizar a PI.

Neste trabalho, serão apresentadas as principais obras de algumas das figuras que tiveram grande influência no advento da $\mathrm{PI}$, bem como comentadores de suas obras. A ação deste grupo foi analisada a partir de categorias teóricas como classe social, relações sociais de produção e intelectuais orgânicos.

\section{RESULTADOS E DISCUSSÕES}

\subsection{A institucionalização da Psicologia e da Psicologia Industrial}

No conjunto das relações sociais de produção do início do século XX foram elaborados avanços técnicos nas forças produtivas que prezavam pela lógica mecânica, matemática e pragmática. Ao avançar sobre esse terreno, o homem-que-trabalha passa a ser interpelado, através da Psicologia Industrial, como sujeito-psico-trabalhador. No caso da Psicologia Organizacional e do Trabalho (POT) os trabalhadores passam a ser tratados como recurso humano psicofísico e psicossocial passível de ser interpelado como tal no campo das relações de produção. 
Indicativo disso foi a perda de força da escola estruturalista e aumento dos adeptos da escola funcionalista da Psicologia (Goodwin, 2005).

Um indicador do processo acima mencionado foi o tipo da literatura produzida no campo da Psicologia entre a passagem do século XIX para o XX, ocasião em que $25 \%$ das comunicações de pesquisa publicadas nas revistas americanas no campo científico em questão tratavam de elementos de Psicologia Aplicada, e menos de 3\% envolviam introspecção (O’Donnell, 1985). Por conta desse contexto somado ao apelo pragmático, o funcionalismo tornou-se mais atraente para fiduciários e curadores das universidades e, também, para o financiamento privado (Idem, 2005). Este ponto permite evidenciar ainda mais a influência econômica nos processos de desenvolvimento teórico e científico da Psicologia orientados para práticas específicas permeada por interesses econômicos de classe. Não é sem motivo que o berço da POT tem como epicentro os Estados Unidos.

Outra afirmação emblemática na transição do século XIX para o XX foi feita por Stanley Hall1, uma figura importante da Psicologia estadunidense: "We need a psychology that is usable, that is dietetic, efficient for thinking, living and working..." (precisamos de uma psicologia que seja utilizável, que seja dietética, eficiente para o pensamento, vida e trabalho) (Hall, 1912, p. 414).

No ano de 1921, foi fundada a New York Associoation of Consulting Psychologists. Ela foi constituída principalmente por psicólogos clínicos, educacionais e por um pequeno núcleo de psicólogos industriais. Em 1930, com o crescente número de psicólogos em áreas aplicadas e o aumento da insatisfação com a American Psychology Association (APA), criada em 1892, a New York ACP foi expandida e, a partir dela, formou-se a ACP (Association of Consulting Psychologists). psicólogos industriais estiveram envolvidos na formação do ACP e participaram das suas reuniões anuais. Em 1936, a presidente da ACP, Gertrude Hildreth (1898-1984), sugeriu que fosse organizada uma comissão de psicólogos industriais com o intuito de criar condições para a melhoria do exercício na área, além de desenvolver um conjunto de normas que fomentassem um código de ética (BENJAMIN, 1997). A consolidação de uma camada de intelectuais orgânicos atuantes da Psicologia Industrial passou, então, a ser organizar a partir da sua respectiva institucionalização.

Em 1937, sob a liderança de Douglas H. Fryer (1891-1960), membros de vários grupos de psicologia aplicada, incluindo a seção clínica da APAs, a ACP e outros grupos locais e estaduais, formaram American Association of Applied Psychology (AAAP). Essa associação cresceu rapidamente e tornou-se a organização dominante nos EUA ligada aos interesses dos psicológicos aplicados. Nela foi criada uma a seção Industrial e Comercial, mais precisamente a seção D (Idem)2.

AAAP seção D, Industrial e Comercial, identificou oito áreas nas quais os membros poderiam fornecer serviços:

1) Estudos sobre os requisitos para as ocupações;

\footnotetext{
${ }^{1}$ Em 1892, G. Stanley Hall convidou cerca de 30 psicólogos e filósofos para uma reunião com o objetivo de fundar a American Psychological Association (APA) (Cf. EVANS et al, 1992).

${ }^{2}$ Além da seção Industrial e Comercial, houve outras três seções: uma clínica, uma de consultoria e uma educacional. Posteriormente, foi adicionada uma seção de psicologia militar (BENJAMIN, 1997).
} 
2) Desenvolvimento e utilização de testes e outras técnicas científicas na alocação de trabalhadores;

3) Formulação dos melhores métodos de aplicação da energia humana no trabalho;

4) Organização e sistematização de programas de formação para assegurar o completo desenvolvimento e o uso mais eficiente da capacidade individual nas atividades de trabalho;

5) Determinação de elementos que proporcionem condições ideais de trabalho;

6) Análise das características da organização industrial com a finalidade de determinar quais são os melhores tipos de adaptação para servir tanto a objetivos humanos econômicos e sociais, e, de modo mais geral, a organização como um todo;

7) Exame e controle de elementos motivadores, tanto no caso de trabalhadores, como no de administradores, que influenciam as relações de produção no sentido de harmonizá-las;

8) Análise dos fatores humanos que influenciam a procura e venda de mercadorias, através da aplicação de técnicas científicas de pesquisa de mercado e no campo da publicidade ${ }^{3}$.

Disso é possível observar que foram abertos precedentes para que a Psicologia fosse apropriada pelos interesses da burguesia industrial e que a Psicologia Industrial se institucionalizasse. Diante disso, formalizou-se a criação de um subcampo e permitiu que este chegasse a um novo patamar de organização de seus recursos materiais ideológicos e de constituição de seus respectivos intelectuais orgânicos, seus porta-vozes.

\subsection{A formação e ação de quadros de intelectuais orgânicos da Psicologia Industrial}

Diante do contexto mencionado anteriormente, serão apresentadas situações em que figuras estadunidenses centrais que estiveram envolvidas com o projeto de controle comportamental dos empregados no início do século XX admitem a necessidade das ciências gerenciais e seus representantes (administradores, supervisores e gerentes) de se apropriarem de teorias e técnicas de Psicologia.

Dentre as principais figuras atreladas à consolidação da incorporação de elementos da Psicologia nas relações de produção industrial no contexto da autointitulada Administração Científica, pode-se mencionar Hugo Münstenberg (1863-1916). Eis uma de suas quanto à utilização de elementos oriundos da Psicologia nas relações de produção:

Um teste experimental pode decidir em que condições um contínuo trabalho efetivo pode ser garantido por mais tempo e em quais condições mentais o indivíduo pode melhor realizar sua tarefa. Os métodos para estudar a curva de fadiga no trabalhador individual, ou as condições para um trabalho muscular mais preciso, além de centenas de dispositivos semelhantes, estão hoje já à disposição do laboratório mental; contudo, provavelmente, por um bom tempo o contramestre ainda se considerará melhor capacitado em tais questões do que o próprio psicólogo (Münstenberg, 1909, p. 91).

\footnotetext{
${ }^{3}$ Relatório da AAAP de 1938 cit. in BENJAMIN, 1997, p. 463. Tradução livre do inglês.
} 
Hugo Münsterberg estabeleceu as bases e justificativas da primeira fase da Psicologia Organizacional e do Trabalho: a Psicologia Industrial e sua apropriação pela Administração Científica ${ }^{4}$ associadas a Taylor e Fayol $^{5}$. Münstenberg articulou as habilidades dos novos empregados às demandas de trabalho da organização. Sua abordagem psicológica e a eficiência industrial estavam diretamente ligadas e resumiram-se em três pontos principais: 1) o melhor homem, 2) o melhor trabalho e 3) o melhor resultado (Münsterberg, 1922). Também abordou assuntos como a orientação vocacional, gerenciamento de pessoal, motivação dos empregados e o modo como a monotonia e a fadiga produziam efeitos nos níveis de produtividade destes. Por exemplo, ele chamava a atenção de que:

[...] trabalhadores que realizavam tarefas em máquinas deveria ter a velocidade de suas reações testadas, ou a precisão de suas percepções, ou ainda a rapidez de suas decisões. Para o exame de cada capacidade mental os laboratórios deveriam se utilizar de instrumentos e métodos apropriados (Idem, p. 88).

Contemporaneamente se inicia o processo em que Lilian Gilbreth e Frank B. Gilbreth transferiram resultados de suas experiêcias em psicofísica para o setor industrial em 1911 realizando um estudo sistemático de movimentos corporais dialogando com o trabalho que tinha sido desenvolvido anteriormente por F. W. Taylor (1856-1915) ${ }^{6}$. Os trabalhos de Münstenberg e do casal Gilbreth estão contextualizados no momento em que as forças produtivas do capitalismo tinham os Estados Unidos como epicentro. Todo esforço em incorporar teórica e ideologicamente elementos da Psicologia Industrial ocupava a função de potencializar as margens de mais valia absoluta nas relações de trabalho, pois a tentativa era obter maior controle das condições psicológicas para aumento intensificação da produtividade dos empregados. Uma afirmação feita por Frank Gilbreth deixa isso claro: "There is no waste in the world that equals the waste of needless, ill-directed and innefective motions" (Não há desperdício no mundo que se assemelhe ao desperdício de desnecessário, mal direcionado e ineficaz dos movimentos) (Gilbreth, 1917, p. 1).

A necessidade de elaborar mecanismos cada vez mais precisos sobre as realções de produção veio com o desenvolvimento das forças produtivas no contexto estadunidense. Não é sem razão que os trabalhos de Münstenerg e do casal Gilbreth foram realizados no contexto de desenvolvimento da chamada Administração Científica, que nada mais é a criação de novas formas de exploração da força de trabalho a partir de uma fase específica do modo de produção capitalista no contexto industrial estadunidense.

Entre o final do século XIX início do século XX, ao mesmo tempo em que foram sendo desenvolvidas técnicas, conteúdos e avanços nas chamadas ciências gerenciais entre a alta administração das organizações empresariais, os trabalhadores, por sua vez, também passavam por um momento de adequação/readequação das suas estratégias cooperativas e organizativas de trabalho. Entre eles combinava-se uma série de rituais de forma a solidarizarem-se com as condições de trabalho com as quais tinham de se haver cotidianamente. Havia por trás das relações

\footnotetext{
${ }^{4}$ Movimento que buscou aplicar elementos da ciência na prática gerencial e, ao mesmo tempo, realizou na prática administrativa investigações para torná-la objeto da ciência. Tal ponto será desenvolvido no capítulo posterior.

${ }^{5}$ Considerados precursores da Administração Científica.

${ }^{6}$ Cf. VIEIRA, 2018.
} 
informais dos trabalhadores, formas de organização com dinâmica psicossocial. Exemplo disso pode ser mencionado o caso dos trabalhadores da Midvale Steel Company, uma indústria de construção de máquinas. No final do século XIX, seus operários trabalhavam sob o regime de pagamento por peça. Nessa condição os operários, com o intuito de baixar o referencial nivelador que fixava a quantidade de peças por empregado, articulavam-se em meio a acordos informais:

Quase todos os trabalhos dessa fábrica eram feitos, há muitos anos, pelo sistema de pagamento por peças. Como era usual então, e, de fato, como também é comum nas maiorias das fábricas do país, a oficina era realmente dirigida pelos trabalhadores e não pelos patrões. Os operários, em seu conjunto, tinham cuidadosamente planejado como os trabalhos deviam ser executados e estabelecidos o ritmo para cada máquina que correspondia, mais ou menos, a um terço de razoável produção diária. Todo novo trabalhador, ao ingressar na fábrica, era instruído por companheiros sobre sua função no trabalho que ele devia fazer e advertido de que, se não obedecesse a essas instruções, podia estar certo de que seria substituído dentro de pouco tempo (Taylor, 2012, p.47).

Dentre os trabalhadores que se organizavam da maneira citada na Midvale Steel Company estava, ninguém mais, ninguém menos, do que Frederick Taylor, ainda na condição de mestre dos tornos, mas que, anteriormente, tinha ingressado como operário. Isto revela que, antes de produzir sua maior obra, Princípios de Administração Científica, Taylor tinha conhecimento de como se davam as relações informais entre os trabalhadores e as formas organizativas desempenhadas por esses para lidarem com as bases de nivelamento da produção. Portanto, Taylor sabia como tais estratégias funcionavam e, declaradamente em seu livro, levou isto em conta quando desenvolveu as reflexões em sua obra clássica.

Pouco tempo depois, Taylor assumiu o cargo de contramestre na Midvale Steel Company. Logo em seguida, seus ex-companheiros operários, ao saberem desse fato, parabenizam-no e disseram que estavam certos de que Taylor sabia das estratégias do trabalho por peças e que, se ficasse do lado desses, tudo correria bem. Entretanto, Taylor advertiu-os que, a partir daquele momento, estava servindo à direção. A relação, antes amistosa, tornou-se, então, conflituosa.

Para conseguir aumentar os níveis de produtividade, Taylor passou a demitir os trabalhadores que se mostravam mais persistentes e a reduzir os salários daqueles trabalhadores que resistiam em aumentar as bases niveladoras dos índices produtivos diminuindo o preço pago por peça. Resultado: após três anos no cargo, conseguiu aumentar os rendimentos e, em alguns casos, fez com que os empregados aumentassem em dobro a produtividade sendo, a partir disso, novamente promovido. Entretanto, antes desse fato, foram sendo criados muitos conflitos e mesmo ameaças entre empregados e Taylor.

O que foi mencionado anteriormente revela que as relações solidárias e informais entre os trabalhadores da Midvale, na medida do possível, foi uma estratégia utilizada para colocar limites nos níveis de produtividade e na intensidade do trabalho sobre eles impostos. As relações sociais e pessoais entre os empregados das organizações empresariais fizeram surgir esforço das ciências gerenciais em elaborar formas de controlar as relações de produção evitando tais "obstáculos". As ciências gerenciais e a Psicologia Industrial passaram a depositar cada vez mais esforços no sentido de regular ou controlar o comportamento dos trabalhadores no interior da organização.

Não é sem motivo que em sua principal obra, Taylor dedica um pequeno trecho no qual defende que o controle comportamental e emocional dos empregados deva ser objeto a ser 
explorado pelas ciências gerenciais. Numa pequena seção intitulada Psicologia dos trabalhadores do seu livro Princípios da Administração Científica ele revela o seguinte:

Há outro tipo de investigação científica, a que aludimos várias vezes neste livro e que deve ser objeto de especial atenção; trata-se do estudo cuidadoso dos motivos que determinam a conduta dos homens. A princípio, pode parecer que é assunto de observação e julgamento individual e não propriamente de investigações científicas exatas. É verdade que as leis resultantes de experiências dessa espécie, pelo fato de tratar-se de organismo muito complexo - o ser humano -, estão sujeitas a grande número de exceções, ao contrário do que sucede com as relativas às coisas materiais. $E$, entretanto, existem inquestionavelmente leis desta espécie, que aplicam a um grande número de pessoas e que, quando claramente definidas, são de grande valor para orientar a direção dos homens (Idem, p. 87, grifos nossos).

Outro ponto que chama a atenção na obra de Taylor é a estratégia de recorrer ao discurso científico como forma de legitimação de sua teoria-ideológica, como se o fato de tratar-se de um estudo de tal categoria, equivaleria a uma espécie de verdade-natural. Tanto que, ao evidenciar os objetivos dos seus estudos, ele afirma que um deles é "provar que a melhor administração é uma verdadeira ciência, regida por normas, princípios e leis claramente definidos, tais como uma instituição" (Idem, p. 23, grifos nossos). Além disso, pretensiosamente sublinha que não existe antagonismo entre classes na Administração Científica e, sim, uma convergência de interesses, pois, segundo Taylor, "a administração científica tem, por seus fundamentos, a certeza de que os verdadeiros interesses de ambos são o único e mesmo" (Idem, p. 25). É possível notar o esforço de se colocar numa situação de neutralidade e negar a existência da contradição fundamental entre capital e trabalho.

Na mesma obra, Taylor já esboçava princípios que tentavam intervir sobre aspectos psicológicos dos trabalhadores no campo das relações de produção. Tal esforço se faz presente num trecho do seu livro com o título Efeitos sobre a moral dos trabalhadores. Em determinado ponto desta parte do livro, afirma que os seus estudos científicos foram capazes de revelar que os trabalhadores perdem "ambição e iniciativa" quando colocados em grupos, diferentemente de quando são "tratados separadamente como pessoas" (Idem, p. 60) e, desse modo, enfatizando o elemento comportamental dos empregados. Logo em seguida continua:

A análise cuidadosa demonstrou que, quando os trabalhadores estão reunidos, tornam-se menos eficientes do que quando a ambição de cada um é pessoalmente estimulada; que quando os homens trabalham em grupo sua produção cai invariavelmente ao nível, ou mesmo abaixo do nível, do pior homem do grupo; e que todos pioram em vez de melhorarem o rendimento com a colaboração. Por esta razão foi expedida uma ordem geral na Bethlehem Steel Works que proibia trabalharem juntos, em grupo, mais do que quatro homens sem ordem especial do superintendente e que a permissão não podia ir além duma semana (Idem, pp. 60-61).

Taylor procurou sustentar tal afirmação a partir de intervenções experimentais feitas com descarregadores de minérios em vagões. Quando tais empregados trabalhavam juntos num mesmo vagão, o ritmo médio de todos os trabalhadores sempre era inferior do que quando cada 
trabalhador era colocado isoladamente em um vagão. Quando trabalhavam sozinhos, a média de toneladas de minérios descarregados era maior. Lembrando que o pagamento era por tonelada descarregada. Tal situação, embora ainda de maneira embrionária, revelava que as relações informais entre trabalhadores e os resultados tácitos dessas relações influenciavam o comportamento dos empregados quanto ao nível de produtividade. Nesse caso, a dinâmica do grupo era evitada quando se isolava os empregados.

Despontavam-se, então, princípios que mais tarde estruturariam estudos sobre os efeitos da moral do grupo no clima organizacional e na sua relação com o objeto das ciências gerenciais.

Contemporâneo de Taylor, também pode ser destacado Henry Gantt (1861-1919). Ele esteve presente e colaborou com as experiências daquele na Midvale Steel. Em suas reflexões já advertia que existem outros fatores para além dos incentivos financeiros que exercem influência sobre o comportamento dos empregados (Cf. URWICK, 1956). Seu estudo intitulado Training Workmen in Habits of Industry and Cooperation, publicado em 1908, mencionou a importância de intervir no que ele chamou de "a psicologia das relações com os empregados" (Gantt, 1908). Segundo George, o objetivo de Gantt era de que a administração deveria ter "responsabilidade na educação e adestramento dos trabalhadores, para que se tornassem especializados, adquirissem melhores hábitos de trabalho, perdessem menos tempo e se tornassem mais idôneos" (1977, p. 152).

Além de Taylor e Gantt, Henry Ford foi um dos que admitiu a necessidade de controle dos empregados pela via gerencial e comportamental para fins políticos. O sistema por ele criado posteriormente recebeu o nome de Fordismo7. O trecho a seguir é destacado de uma parte de sua obra Os princípios da prosperidade, em que o autor revela a preocupação com a ação sindical e com seus respectivos líderes e projeta a seguinte consideração acerca destes:

Um só grupo é forte nas federações: os operários que vivem das federações. Alguns deles são riquíssimos. Outros têm interesse em atuar sobre os negócios das grandes instituições financeiras. Outros são radicais em seu chamado socialismo, que raiam ao bolchevismo e à anarquia, pois os salários pagos pelas federações lhes permitem não trabalhar e consagrar tempo inteiro e toda sua energia à propaganda subversiva. Todos gozam de certo prestígio e poder que jamais alcançariam no curso normal da concorrência (FORD, 1964, p. 180).

Diante disso, revela que é preciso a consolidação de uma educação nos EUA que forme líderes capazes de solidificar um grupo de supervisores e administradores que tivesse capacidade de "liderar" o "trabalho". Tal declaração revela sua atenção em relação à formação de "líderes" capazes de influenciar o comportamento e a conduta dos empregados:

O verdadeiro líder do trabalho é o que dirige o trabalho para uma alta eficiência e valorização em vez de desviá-lo para o caminho das greves, das lutas estéreis e da miséria. A união trabalhista que se justificará em nosso país será uma liga de todos cujos interesses

\footnotetext{
7 Trata-se de sistema racionalização das relações sociais de produção e do uso das forças produtivas criadas através de inovações técnicas e sobre o controle da força de trabalho articuladas com a produção em massa e com o consumo em massa. Duas bases fundamentais foram a especialização das tarefas exercidas pelos trabalhadores e o desenvolvimento da linha de produção que passou a organizar o ritmo de trabalho (PINTO, 2010).
} 
são solidários e só repousam na eficiência do serviço que prestam (Idem, 1964, p. 180, grifos nossos).

Embora Ford não mencione a Psicologia ou as ciências comportamentais nesse trecho de forma direta, o objeto aqui é a influência comportamental por meio da atitude, ação, influência e coerção simbólica através de técnicas de "liderança". Tal preocupação revela que Ford reconhecia a necessidade de criar sujeitos portadores da confiança de tal modo que pudessem ocupar o papel de sujeitos-enunciantes das teorias-ideológicas gerencialistas que os trabalhadores (sujeitosenunciados) deveriam adotar como referencial para conduta no interior das organizações baseadas nas determinações e controle dos primeiros.

Outra figura que, embora não associada aos grandes nomes da Administração no início do século XX, merece menção no processo que foi sendo desencadeado pela aliança entre Administração e Psicologia na primeira metade do século XX é Mary Parker Follett (1868-1933). Sua posição quanto ao problema "humano" da organização era que as sociedades produtivas devem utilizar, em suas fundamentações, o reconhecimento dos desejos dos indivíduos e dos grupos.

Segundo Follett, os empregados são motivados pelos mesmos fatores que os motivam fora do seu emprego. A estadunidense também afirmava que o ato de subordinação poderia ofender as emoções dos homens, o que ocasionaria efeitos negativos em processos colaborativos. Follett, desse modo, contribuiu para a ampliação do alcance do gerenciamento dos empregados no âmbito comportamental. De certo modo, as concepções de Mary P. Follet foram influenciadas pelas teses da Administração Clássica, pois admitia a existência de princípios gerais aplicáveis na indústria como em qualquer outra forma de organização. Contudo, ao incorporar em suas análises uma abordagem psicológica, prepara de certa forma o terreno para as concepções da Escola de Relações Humanas ${ }^{8}$. Mary afirmou, na primeira década do século $X X$, que a Administração não havia feito uso devido dos conhecimentos desenvolvidos pela Psicologia, não apenas no sentido de explicar aspectos comportamentais dos trabalhadores, mas também para obter melhor desempenho dos empregados. A partir de suas posições, Mary Follet articulou duas questões: 1) $\mathrm{O}$ que se pretende que as pessoas façam? 2) Como controlar e orientar cientificamente a conduta humana no trabalho? (In: Glossário FGV9).

Ainda sobre o contexto do início do século XX, Idalberto Chiavenato, um dos estudiosos sobre a história da Administração, embora trate a contestação dos trabalhadores no período em questão como um suposto fruto da democracia estadunidense, afirma que os limites da Teoria Clássica da Administração, colocados à prova com a reação dos empregados, forçou os especialistas das ciências gerenciais e comportamentais a desenvolverem novas formas de gerenciamento comportamental no contexto das relações de produção:

A Teoria Clássica e a Administração Científica nunca foram pacificamente aceitas num país democrático como os Estados Unidos, onde trabalhadores e sindicatos passaram a considerá-los um meio sofisticado de exploração dos empregados a favor dos interesses patronais (Chiavenato, 2001, p. 135).

\footnotetext{
${ }^{8}$ Conjunto de teorias gerenciais que foram desenvolvidas a partir de meados da década de 20 do século XX.

${ }^{9}$ Disponível em <http://www5.fgv.br/ctae/publicacoes/Ning/Publicacoes/00Artigos/JogoDeEmpresas/Karoshi/glossario/FOLET.html>: Acessado em 15/01/2016.
} 
Também é importante lembrar as acepções de Elton Mayo (1880-1949) sobre a incorporação da Psicologia do Trabalho nas relações de produção, líder da chamada experiência de Hawthorne ${ }^{10}$. Mayo (1880 -1949) nasceu na Austrália e teve formação em Psicologia. Em 1923 foi para a Universidade da Pensilvânia onde teve contato com as questões industriais estadunidenses e desenvolveu suas respectivas preocupações com assuntos gerenciais e políticos entre a burguesia industrial americana e os sindicatos. Em 1925, a convite de Wallace Donham (1877-1954), o segundo reitor da Harvard Business School, passou a lecionar em tal universidade. Entre 1927 e 1947 se empenhou em experimentos ligados ao Departamento de Pesquisa Industrial de Harvard tendo como objeto a usina da Western Eletric Company. Tal investigação foi financiada pela Fundação Rockefeller, criada por John Davinson Rockefeller (1839-1937), que junto com seu irmão fundou a Standard Oil Company. Rockefeller tornou-se o homem mais rico daquele período e foi o primeiro estadunidense a ter mais de 1 bilhão de dólares (Segall, 2001) e, desse modo, tornou-se referência da burguesia dos Estados Unidos no início do século XX.

A experiência, segundos os envolvidos, revelou que a atenção que foi dada aos empregados no decorrer da pesquisa e as reações que isto projetou no comportamento desses foi determinante nas variações dos níveis de produtividade. A ideia de dar atenção aos empregados e as demais conclusões dos pesquisadores mencionadas desembocou em mudanças significativas nas relações estabelecidas entre a alta administração e os empregados, trazendo à tona o enfoque sobre as questões subjetivas envolvidas nas relações de trabalho. Tal pressuposto passou a ser estrategicamente utilizado de forma a aquietar os ânimos contestatórios do período em questão.

Além do posicionamento político mencionado acima, Mayo apontou, após a pesquisa, que os elementos lógicos ocupam um espaço de menor importância em relação aos elementos emocionais. A partir de então, além das questões psicofísicas, a Psicologia industrial passa a se atentar cada vez mais para dimensões subjetivas da constituição psíquica dos empregados. Diante disso, Mayo passou a afirmar que a formação dos gerentes deveria proporcioná-los condições para que pudessem gerenciar as relações humanas dos empregados (MAYO, 1972).

Para gerenciar a suposta integração entre capital e trabalho, segundo Mayo (1972), seria necessário que a sociedade capitalista formasse uma boa quantidade de homens de ciência capazes de gerenciar tal relação de modo a evitar conflitos. Tal afirmação comprova a preocupação na formação de quadros de especialistas e intelectuais orgânicos para organizar as relações de produção na nova fase do capitalismo industrial estadunidense.

Além do que foi mencionado, dois pontos com implicações diretas no terreno da Psicologia foram desenvolvidos após Hawthorne. O primeiro foi que os métodos de utilização de supervisores foram fundamentais enquanto estratégia para evitar que fatores psicológicos produzissem as chamadas ineficiências produtivas. Por conta disso, começaram a ser desenvolvidos cursos para treinamento de supervisores de modo a instrumentá-los e orientá-los para que pudessem compreender aspectos psicológicos entre os trabalhadores (Homans, 1967).

Outro ponto destacado por Mayo foi que, de acordo com um dos elementos fundamentais dos fatores psicológicos em que a administração de empregados devia intervir no processo

\footnotetext{
${ }^{10}$ Foi uma experiência realizada usina da Western Eletric Company, localizada na cidade de Chicago, mais precisamente no bairro de Hawthorne. A investigação inicial era analisar o impacto da iluminação no nível de produtividade dos empregados. Contudo, o desenrolar da pesquisa acabou, segundo os pesquisadores envolvidos, sendo revelado que os níveis de produtividade estavam relacionados à atenção dada aos empregados, ou seja, a partir de uma variável de caráter psicossocial. especificamente, no bairro Hawthorne.
} 
produtivo foi sobre a criação de uma relação de identidade entre trabalhador e organização, eliminando qualquer indício de contradição e reforçando cada vez mais uma dimensão uníssona nas relações de produção. O objetivo fundamental foi criar um vínculo psicossocial e emocional entre empregados para com a organização. Para isso foi necessária a criação de novas estratégias comunicacionais, simbólicas e subjetivas para gerenciar os trabalhadores não apenas no âmbito da formalidade hierárquica tradicional e psicofísica, mas também na dimensão informal e emocional.

No mesmo período, o estadunidense Horace Drury (1888-1968), em sua obra intitulada History and Criticism of Scientific Management, publicada em 1915, embora criticasse alguns aspectos da Administração Científica no que diz respeito aos seus efeitos sobre os trabalhadores, afirmou que a principal contribuição dessa escola foi ter iniciado a transferência do pensamento administrativo das máquinas para os homens (DRURY, 1915).

Três anos depois da publicação do texto de Drury, Ordway Tead (1891-1973), professor, administrador e conferencista em universidades, começa a escrever textos sobre administração e educação. Seus primeiros textos tratavam de "aspectos de comportamento da natureza humana" e seus textos escritos posteriormente tentavam explorar a forma como tais elementos poderiam ser aplicados no processo criativo e produtivo, ou seja, a concepção de humano enquanto meio para a consolidação de tal processo como instrumento, e não como premissa. Drury, em seu texto Instincts in Industry, segundo George (1974), fez um estudo da psicologia da classe trabalhadora tentando

[...] mostrar as relações entre os temores, ambições, atitudes e realizações dos trabalhadores, por uma parte, e as realidades da natureza humana, por outra. O seu objetivo foi apurar se o comportamento na indústria poderia se tornar mais inteligível, à luz da compreensão existente dos hábitos e predisposições psicológicas. A sua conclusão foi que os instintos têm, a longo prazo, uma influência tão grande na determinação da conduta das pessoas quanto qualquer outro fator, individualmente considerado (Drury, 1929 Apud George, 1977, p. 179).

Contemporâneo de Drury e Tead, destacou-se também Norman Raymond Frederick Maier (1900 - 1977). Foi professor de Psicologia da Universidade de Michigan. Sua formação passou pela ênfase na chamada Psicologia Industrial. Uma de suas obras foi Princípios de Relações Humanas e Sua Aplicação na Vida das Empresas, cuja primeira publicação foi feita em 1952. Nela fez uma afirmação de caráter político em relação à guerra de posição entre líderes sindicais e líderes formados através da Teoria das Relações Humanas: "indubitavelmente, o poder exercido pelos sindicatos tornou aparente esta necessidade e os líderes das empresas sentem que eles próprios estão competindo com a liderança dos sindicatos pela lealdade de seus empregados" (Maier, 1966, p. 15 , grifos nossos).

Enquanto alguns sindicatos apresentavam um projeto político contestatório ao modo de produção capitalista com contornos tayloristas, ou ao menos a algumas de suas implicações, parte de donos de grandes indústrias estadunidenses buscou nos resultados de investigações comportamentais e subjetivas que estavam sendo desenvolvidas pela Psicologia uma alternativa para apresentar um esquema prático, político e ideológico nesse âmbito específico. Para tanto, passaram a reconhecer a necessidade de elaborar a formação de indivíduos capazes de colocar em uso tal projeto de maneira a se contrapor o movimento trabalhista de um novo modo, visto que 
experiências anteriores mostraram que processos meramente repressores podem apresentar resultados imediatos, mas sem eficiência a longo prazo (Idem).

Maier, em sua obra Psicologia Industrial, discute a forma como os sindicatos se organizam em torno daquilo que ele chama de "frustração", objeto da Psicologia e Psicossociologia. Segundo Maier (1960), esse sentimento coletivo é o que leva muitos grupos a se organizarem em movimentos sociais. A partir desse pressuposto, o autor afirma que essa lógica é aplicável na compreensão do movimento sindical. Disto Maier desenvolve a ideia de que os Psicólogos Industriais devem se esforçar para compreender essa relação e, desse modo, orientar tal frustração em direção ao uso gerencial pelas organizações empresariais. No desenvolver do seu raciocínio, Maier apresenta duas concepções acerca da forma como a frustração dos trabalhadores pode ser encarada: uma positiva e outra negativa. A positiva diz respeito a um movimento que busca articular a frustração em torno de questões que não coloquem em cheque as relações de poder entre capital e trabalho, ao mesmo tempo em que aponta para uma solução que permaneça dentro dos limites colocados pelos especialistas em gerenciamento; a negativa diz respeito às frustrações que são orientadas para uma conduta mais radical e que se contrapõem às estruturas de poder que sustentam as relações de produção dominante. Para ilustrar essa polaridade por ele construída, utiliza dois casos de organizações sindicais: a American Federation of Labor (A.F.L.) como exemplo que ele entendia como positivo e a Industrial Workers of the World (I.W.W. $)^{11}$ como exemplo negativo. O próprio Maier coloca essa distinção do seguinte modo:

Durante o mesmo período, a A.F.L. organizou trabalhadores mais competentes em comparação à I.W.W. O programa daquela se fazia através de propostas de melhores salários e condições de trabalho, ao invés de apoiar a revolução e a derrocada do capitalismo. No lugar de falar "toma as riquezas que produz!", a A.F.L. perguntava: "quer ter uma casa melhor e mais coisas para fazer feliz a sua família?. Seus dirigentes chegaram algumas vezes a serem considerados heróis e suas reuniões foram menos conflituosas (Maier, 1960, p. 113) ${ }^{12}$.

Como proposta para solucionar essa reação "agressiva" por parte de atitudes radicais de sindicatos e/ou grupo de trabalhadores, Maier propõe um método de catarse como forma de aliviar a frustração e, desse modo, desestimular a atitude opositiva:

O termo catarse se refere ao alívio da frustração que se cria pela mera expressão dessa mesma frustração. Nos estudos Hawthorne foi sugerido aos entrevistadores que facilitassem aos empregados formas de exteriorizarem sua hostilidade e que desabafassem. Uma das funções da terapia é criar uma situação na qual o paciente se sinta livre para exteriorizar seus sentimentos reprimidos91. Para que a frustração dê lugar a tensões emocionais e crie um estado que a substitua por uma conduta racional, é preciso intervir a partir desse processo a fim de que o indivíduo retome sua racionalidade (Idem, p. $116)^{13}$.

\footnotetext{
${ }^{11}$ Seus membros eram constituídos em grande medida por trabalhadores imigrantes das indústrias da Califórnia e por trabalhadores na zona leste dos Estados Unidos. Eram trabalhadores que sofriam restrições mais amplas em termos de seguridade social, baixo nível de renda. Eram trabalhadores excluídos da American Federation of Labor, a maior organização trabalhista dos Estados Unidos em meados do século XX.

12 Tradução livre do espanhol.

13 Tradução livre do espanhol.
} 
Posteriormente, Maier dedica um pequeno trecho do seu livro a uma parte intitulada As demandas dos sindicatos frente aos desejos dos empregados. Ao problematizar tal assunto, o psicólogo estadunidense inicia com a seguinte pergunta: "Por que os homens fazem greve para reivindicar maiores salários e menos horas de trabalho sendo que esses não são os elementos de maior importância?" (Idem, p. 408). O julgamento que ele elabora diante de tal questão é o seguinte:

A resposta, em parte, parece ser a de que se o trabalho é desagradável, os homens exigem incentivos econômicos extraordinários para superar estas condições e pedem redução do horário de trabalho de modo que possam ficar longe do desagradável o maior tempo possível (Idem, p. 408).

De modo complementar, Maier afirma que "outra causa que contribui para que peçam maiores salários é o desejo de equidade" (p. 408). Por conta disso, chama a atenção dos Psicólogos Industriais para que esse "desejo de equidade" seja explorado como objeto de estudo. Para tanto, sugere que a relação entre trabalhadores e sindicatos seja estudada e ajustada pelos psicólogos de forma que o fundamento da relação aí presente seja apropriada para conhecimento e uso gerencial:

O estudo do que as pessoas dizem querer de um trabalho demanda que atenção seja dirigida para aquelas necessidades que não surgem do estudo dos temas de um acordo direção-sindicato e, desta forma, nos munir da compreensão das motivações reais dos trabalhadores (Idem, pp. 408 e 409 grifos nossos).

Maier entendia que os sindicatos cumpriam uma função psicossocial. A adesão de certos empregados se realizava por conta dessa função. Daí Maier propor que a organização passasse a oferecer elementos motivadores para que os empregados não precisassem recorrer aos sindicatos para tanto.

Daqui em diante serão apresentadas algumas considerações acerca dos dados e informações que foram mencionados anteriormente acerca da formação de camadas técnicoteóricas e instituições ligadas ao desenvolvimento da Psicologia Industrial. Tal análise será feita a partir dos conceitos de classes sociais, relações sociais de produção e intelectuais orgãnicos.

\subsection{Intelectuais orgânicos da Psicologia Industrial e suas funções ideopolíticas}

Algumas considerações que podem ser realizadas através dos dados vistos anteriormente são as seguintes: a grande preocupação dos proprietários e responsáveis pelas empresas em se fortalecerem frente à queda de braço entre as formas organizacionais dirigidas por managers apoiados pelo desenvolvimento das ciências gerenciais e as organizações de trabalhadores orientadas pelos sindicatos ou por organizações informais entre estes no interior das fábricas. As teorias-ideológicas desenvolvidas pela Psicologia Industrial foram estimuladas por interesses econômicos de classe que dialogam entre si num processo não passível de ser fracionado, embora cada um desses fatores exerça especificidades dentro do contexto em questão. 
Todas essas questões e preocupações se tornaram o carro-chefe para o desenvolvimento de teorias gerenciais que passaram a interpelar e reconhecer os sujeitos presentes nas relações de produção como recurso detentor de aparelho psicossocial ${ }^{14}$. Dado o reconhecimento dessas características, ela foi sendo incorporada-subordinada pelo raciocínio gerencialista que despontava nos EUA. Raciocínio esse que tornou-se dominante em âmbito mundial nas teorias administrativas empresariais. Diante disso, a Psicologia do Trabalho tornou-se uma teoriaideológica entrecruzada-subordinada às teorias-ideológicas gerencialista, dada a força que essa desempenhou na estrutura econômica-social estadunidense. Contudo, tais conjuntos técnicoteóricos só puderam ser colocados em prática e ganhado espaço através da formação de quadros de intelectuais orgânicos, de sujeitos enunciantes que pudessem colocá-los em prática. Ou seja, por meio de porta-vozes dos interesses de classe da burguesia industrial. Alguns Psicólogos Industriais ocuparam uma função estratégica no campo classista no contexto de transformações que vieram à tona no início do século XX por meio de intervenções com campo psicossocial com o objetivo de oferecer técnicas cada vez mais elaboradas para o controle gerencial dos operários industriais.

A formação de quadros intelectuais, de conjuntos ideológicos-teóricos e de instituições voltadas para tal formação é que fomentaram os recursos materiais ideológicos no campo da Psicologia Industrial no EUA início do século XX. Diante disso, é possível afirmar que o caráter orgânico de classe dos Psicólogos Industriais os tornaram intelectuais orgânicos ligados à burguesia industrial. Relação orgânica essa que Semeraro (2006), baseado em pressupostos gramscianos, entende da seguinte maneira:

Orgânicos, (...), são os intelectuais que fazem parte de um organismo vivo e em expansão. Por isso, estão ao mesmo tempo conectados ao mundo do trabalho, às organizações políticas e culturais mais avançadas que o seu grupo social desenvolve para dirigir a sociedade. Ao fazer parte ativa dessa trama, os intelectuais "orgânicos" se interligam a um projeto global de sociedade e a um tipo de Estado capaz de operar a "conformação das massas no nível de produção" material e cultural exigido pela classe no poder. Então, são orgânicos os intelectuais que, além de especialistas na sua profissão, que os vincula profundamente ao modo de produção do seu tempo, elaboram uma concepção éticopolítica que os habilita a exercer funções culturais, educativas e organizativas para assegurar a hegemonia social e o domínio estatal da classe que representam (...). Conscientes de seus vínculos de classe, manifestam sua atividade intelectual de diversas formas: no trabalho, como técnicos e especialistas dos conhecimentos mais avançados; no interior da sociedade civil, para construir o consenso em torno do projeto da classe que defendem; na sociedade política, para garantir as funções jurídico-administrativas e a manutenção do poder do seu grupo social (Semeraro, 2006, pp. 377-378 grifos nossos).

É nesse sentido que Gramsci (2011) afirma que:

\footnotetext{
${ }^{14}$ Que os indivíduos são reconhecidos pelo seu caráter psicossocial, isso a Psicologia já havia sinalizado. O que aconteceu foi, após o reconhecimento e sua sistematização em um campo científico, a apropriação desse pressuposto no e para o desenvolvimento do gerencialismo.
} 
o empresário capitalista cria consigo o técnico da indústria, o cientista da economia política, o organizador de uma nova cultura, de um novo direito, etc., etc15. Deve-se observar o fato de que o empresário representa uma elaboração social superior, já é caracterizada por uma certa capacidade dirigente e técnica, não somente na esfera restrita de sua atividade e de sua iniciativa, mas também em outras esferas, pelo menos mais próximas da produção econômica (deve ser um organizador da massa de homens, deve ser um organizador da "confiança" dos que investem em sua empresa, dos compradores de sua mercadoria, etc.). Se não todos empresários, pelo menos uma elite deles deve possuir a capacidade de organizar a sociedade em geral, em todo o seu complexo organismo de serviços, até o organismo estatal, tendo em vista a necessidade de criar condições mais favoráveis à expansão da própria classe; ou, pelo menos, deve possuir a capacidade de escolher os "pressupostos" (empregados especializados) a quem confiar esta atividade organizativa das relações gerais exteriores à empresa (Gramsci, 2011, pp. 15 e 16 grifos nossos).

Segundo Tragtenberg (2006, p. 20), a preocupação de Mayo, por exemplo, se voltava para a formação de managers capazes de "dominar os conflitos", dominar a "cisão na alma" que, supostamente, se dá na empresa, instituindo "sólidas relações sociais e cooperações espontâneas", o que ajuda a compreender a inserção de psicólogos do trabalho nas empresas de modo a contribuir para o gerenciamento desse suposto equilíbrio e, desse modo, "exercer funções culturais, educativas e organizativas para assegurar a hegemonia social e o domínio estatal da classe que representam (...)" (Semeraro, 2006, p. 377).

Segundo Tragtenberg em sua obra "Administração, Poder e Ideologia", as Relações Humanas tem sua intervenção baseada em dois aspectos: base de grupo dinâmica e sociometria. A dinâmica de grupo estava voltada para a análise e controle com as influências do "vivido psicoafetivo do grupo". A sociometria era direcionada para a "avaliação quantitativa de grupo escolha e rejeição recíproca de seus membros" (p. 28). É relevante observar que novas abordagens como "sociomentria" a "avaliação qualitativa de grupo", entre outras, são novas teorias ideológicas, representam novos recursos materiais ideológicos e dependem da formação de especialistas capazes de colocá-los em prática. Ou seja, a Ideologia representada pela POT passa por uma recomposição dadas as novas condições das relações de produção, das forças produtivas e da correlação de força entre as classes sociais envolvidas.

Maier, ao afirmar que os desejos que os trabalhadores dirigem aos sindicatos não representam as motivações reais dos trabalhadores, revela algo significativo. Quando diz que as motivações dirigidas aos sindicatos não são as reais, implica em dizer que são falsas no sentido de não atender, de fato, aquilo que os trabalhadores "realmente" desejam. Os Psicólogos Industriais e as ciências gerenciais é que deveriam, segundo Maier, se ocupar de descobrir a "realidade" ou o "fundamento real" de tais desejos e, desta forma, cumprir aquilo que os sindicatos não conseguem por não atingirem as motivações "reais". Motivação, posto desse modo, torna-se um objeto apropriável politicamente. Trata-se de uma disputa de classe no campo psicológico de combater àquilo que os sindicatos representam no campo econômico de classe e no campo psicossocial e, ao mesmo tempo, apropriar-se de princípios oriundos da relação indivíduo-desejo-representação no campo gerencial. Ou seja, há nessa estratégia vislumbrada por Maier a tentativa de fazer com

\footnotetext{
${ }^{15}$ Nota nossa: obviamente esta não era a intenção de Gramsci nestas afirmações, mas destas reflexões é possível reforçar o que foi mencionado anteriormente: que a ideologia da POT está entrecruzada-submetida a práticas e a ideologias econômicas.
} 
que a organização apresente meios e estratégias para atingir os desejos e explorar os elementos motivadores por trás das ações coletivas dos empregados.

Também em relação à preocupação da formação de quadros de liderança para colocar em prática um projeto econômico, Mayo (1972) faz a sseguinte consideração:

Brooks Adams... observou que una sociedad moderna sólo puede mantener un equilibrio estable, en medio de rápidas transformaciones, cuando tiene la seguridad de poseer suficiente número de administradores (de ambos tipos, gubernamental y no gubernamental) dotados "en alto grado de inteligencia generalizadora - un a inteligencia que pueda abarcar una multitud de relaciones complejas - pero", agrega, "inteligencias de este tipo sólo producen, en mejor de los casos, en pequeñas cantidades y a alto precio". Afirma luego que nuestro sistema educativo no ha elevado suficientemente su nivel "salvo en lo concerniente a la ciencia y a la mecánica, y el estímulo relativamente exagerado de la inteligencia científica se ha transformado actualmente en una verdadera amenaza contra el orden, como consecuencia de la inferioridad de la inteligencia administrativa". Es decir, que estamos sufriendo lo que McDougall describió como "unilateralidad" en el desarrollo de una élite. Hemos progresado admirablemente en lo concerniente a la investigación científica y a la formación de hombres de ciencia; pero hemos fracasado por completo en cuanto a promover un desarrollo educativo equivalente, enderezado, a descubrir y formar administradores de capacidad excepecional (Mayo, 1972, p. 160).

É importante registrar o momento em tais investidas por parte de teórico-ideólogos das ciências gerenciais canalizam seus esforços enquanto intelectuais orgânicos da burguesia industrial estadunidense. $O$ sindicalismo de caráter conflitivo nos Estados Unidos veio à tona na virada do século XIX para o XX, sobretudo a partir da Industrial Workers of World. Seus adeptos formaram uma corrente política de trabalhadores que passou a se opor à ideologia e prática da business union da American Federation of Labor (A.F.L.), associação essa que tinha um caráter de sindicalismo reformista.

O sindicalismo no início do século em questão também tomou outras formas nos Estados Unidos, incluindo sindicatos de base como a primeira Auto Workers Unionfomada em 1918 por influência de sindicalistas socialistas. Também foi criada a Liga Sindical (Syndicalist League) formada em 1912 (Idem, p. 107).

Diante das pressões operárias no início do século $\mathrm{XX}$, do discurso democrático estadunidense, da pressão por melhores condições de trabalho, da necessidade de controlar as relações de produção como elemento basilar para o funcionamento do modo de produção em nível estrutural, o gerencialismo voltado ao controle da força de trabalho teve que incorporar elementos morais sob o rótulo de Relações Humanas. Esse moralismo ganhou forma nos discursos que interpelam os gestores idealizados por Ford como homens capazes de liderar os trabalhadores para que fossem desviados das "lutas estéreis" das greves (Ford, 1964). A luta de classes, segundo esse empresário estadunidense, representa improdutividade, enquanto que "A união trabalhista que se justificará em nosso país será uma liga de todos cujos interesses são solidários e só repousam na eficiência do serviço que prestam" (Idem, p. 180). Concebia a luta de classes como recaída às condições de barbárie, enquanto que a associação entre os interesses individuais e corporativos como a melhor saída para uma sociedade regida pela harmonia entre capital e trabalho. 
A coerção física não podia ser mais utilizada como uma estratégia a ser levada a longo prazo dado o contexto conflitivo entre representantes sindicais e representantes do gerencialismo, e pela disputa entre essas pela confiança dos trabalhadores (Maier, 1960). Pelo contrário, a força coercitiva contribuía para evidenciar o conflito entre capital e trabalho, além de pôr em evidência as lacunas e os limites ideológicos existentes nos pressupostos do gerencialismo, mesmo em sua vertente humanista.

Esses eventos, somados a uma série de movimentos sindicais em vários países capitalistas, revelam que o início do século XX foi palco de uma intensa agitação política de classe.

Administrar as relações de produção e as forças produtivas tornou-se uma estratégia eminente para consolidar os Estados Unidos como epicentro do capitalismo mundial. É desse projeto econômico-político que foram desenvolvidas ciências gerenciais e comportamentais, incluindo o campo da POT, originariamente chamada de Psicologia Industrial, como ferramentas teórico-ideológicas sob as quais os sujeitos presentes nas relações de produção passaram a ser interpelados. Esse e outros campos teóricos estiveram envolvidos diretamente na intervenção social do conflito de classe. Sobretudo porque, durante os anos 20 e 30 do século $X X$, momento de consolidação de uma estrutura acadêmica nos EUA, os suportes vieram prioritariamente de recursos privados, seja por fundações ou por meio de proprietários diretos. Posteriormente, houve aumento dos investimentos públicos para fins militares delineados pelo projeto político estadunidense (Vallas, 2001).

Os gestores tiveram que desenvolver formas de relações com os empregados cada vez mais aperfeiçoadas, de modo a conquistar a adesão desses aos projetos dos quadros gerenciais. Nesse sentido vale retomar a afirmação de Norman Maier, figura considerada importante no desenvolvimento da POT: "indubitavelmente, o poder exercido pelos sindicatos tornou aparente essa necessidade e os líderes das empresas sentem que eles próprios estão competindo com a liderança dos sindicatos pela lealdade de seus empregados" (Maier, 1966, p. 15). Esse processo traz à tona

Os Psicólogos plantonistas nas grandes corporações, o surgimento, do conceito de "engenharia social", consultorias por empresas especializadas, tudo isso difunde os princípios de relações humanas na sociedade industrial. Ao homem econômico de Taylor contrapõe-se o "homem psicológico" de Mayo; a preocupação com boas relações humanas ocupa o lugar dos aumentos salariais ou da diminuição da jornada de trabalho: funciona o "narcótico do grande demiurgo" (Tragtenberg, 2005, p. 32).

Desse modo, a Psicologia Organizacional e do Trabalho e a Administração foram sendo constituídas historicamente como áreas do conhecimento até à convergência de ambas ao mesmo projeto econômico-político hegemônico mencionado acima e na sua constituição teóricoideológica com implicações específicas.

Diante das pressões operárias no início do século $X X$, do discurso democrático estadunidense, da pressão por melhores condições de trabalho, da necessidade de controlar as relações de produção como elemento basilar para o funcionamento do modo de produção em nível estrutural, o gerencialismo voltado ao controle da força de trabalho teve que incorporar elementos morais sob o rótulo de Relações Humanas. Esse moralismo ganhou forma nos discursos que interpelam os gestores idealizados por Ford como homens capazes de liderar os trabalhadores para que fossem desviados das "lutas estéreis" das greves (Ford, 1964). A luta de classes, segundo 
esse empresário estadunidense, representa improdutividade, enquanto que "A união trabalhista que se justificará em nosso país será uma liga de todos cujos interesses são solidários e só repousam na eficiência do serviço que prestam" (Idem, p. 180). Concebia a luta de classes como recaída às condições de barbárie, enquanto que a associação entre os interesses individuais e corporativos como a melhor saída para uma sociedade regida pela harmonia entre capital e trabalho.

Além disso, a coerção física não podia ser mais utilizada como uma estratégia a ser levada a longo prazo dado o contexto conflitivo entre representantes sindicais e representantes do gerencialismo, e pela disputa entre essas pela confiança dos trabalhadores (MAIER, 1960). Pelo contrário, a força coercitiva contribuía para evidenciar o conflito entre capital e trabalho, além de pôr em evidência as lacunas e os limites ideológicos existentes nos pressupostos do gerencialismo, mesmo em sua vertente humanista. Do outro lado do conflito, os teóricos-ideólogos da Psicologia Industrial ocupavam posições privilegiadas no processo de disseminação teórica-ideológica gerencial no campo da Psicologia. Sobretudo porque estavam sob o escudo da legitimação do saber especialista consolidado e legitimado pela suposta neutralidade da técnica, além da influência positivista e pragmática na transição do século XIX e XX no contexto em questão.

Em suma, os conflitos entre a classe dominada e as dominantes no campo das relações de produção passaram a ser encaradas como "desvios" no campo da Teoria das Relações Humanas. Diante disso, segundo Mayo, a formação dos gerentes deveria municiá-los com condições para que pudessem gerenciar as relações humanas dos empregados (1972). Ou seja, foram criados especialistas para dizer aos empregados como gerenciar a condição humana (sujeitos psicossociais) diante da organização.

Como visto, desde o início do século XX já era assunto dos meios acadêmicos e científicos da Administração a necessidade de modernização dos processos gerenciais onde se inclui, também, a modernização das formas de gerir o conjunto da força de trabalho. Com a proibição do "chicote", as ferramentas de controle precisaram ganhar novos contornos:

Em vez de serem os "homens do chicote", os gerentes e administradores, segundo Taylor, teriam de desenvolver uma nova filosofia e abordagem da gestão empresarial. Teriam de mudar para uma perspectiva mais ampla e abrangente, a fim de que seus cargos incorporassem as funções de planejamento, organização e controle (George, 1977, p. 133).

Em meio a esse quadro social geral, o domínio sobre o corpo passou a ser considerado insuficiente. É nesse momento que se tornou mais contundente a necessidade das ciências gerenciais incorporarem, em suas estratégias, elementos que permitissem reformular novas formas de controle sobre os "recursos humanos". Nesse ínterim, o desenvolvimento de estudos oriundos da Psicologia serviu como uma estratégia utilizada para incursão da ação administrativa em torno da dimensão subjetiva. 


\section{CONCLUSÃO}

Não é de hoje que a preocupação com as questões psicossociais e subjetivas dos empregados são objeto de atenção. Intervenções a partir de dinâmicas de grupos, de estratégias motivacionais e gerenciamento dos aspectos subjetivos, dentre outros, são resultado da formação de um quadro de intelectuais orgânicos cujo pressuposto originário se deu no início do século XX. Os novos referenciais são refinamentos ideoteóricos que foram se adaptando às circunstâncias do desenvolvimento das forças produtivas durante o século $X X$ e se estendem até hoje. $O$ grande avanço no controle gerencial e subjetivo sobre os empregados se tornaram mais sofisticados, mas permanecem sob o mesmo pressuposto do qual partiu a Psicologia Industrial: a necessidade de entender os empregados como sujeitos-trabalhadores-psicossociais e, desse modo, desenvolver mecanismos sofisticados de gerenciamento dos empregados no campo psicossocial. Em sua, a ação das camadas de intelectuais orgânicos direcionadas a tal atividade, desempenharam e continuam desempenhando funções nodais nas relações sociais de produção.

\section{REFERÊNCIAS}

BENJAMIN, L. (1997). Organized industrial psychology before Division 14: The ACP and the AAAP (1930-1945). Journal of Applied Psychology, vol. 82, no 4, pp. 459-466.

BRINGMANN, W \& TWENEY, R. (1980). Wundtstudies. Toronto: Hogrefe.

CHIAVEnAtO, I. (2001). Teoria Geral da Administração. Vol. 1. Rio de Janeiro: Campus.

DRURY, B. (1915). Scientific management: a history and criticism. New York: Columbia University. Disponível em: <https://ia802703.us.archive.org/23/items/scientificmanage00drurrich/scientificmanage00d rurrich.pdf>. Acessado em 05/11/2015.

FORD, H. (1964). Os princípios da prosperidade. São Paulo: Brand.

GILBRETH, F; GILBRETH, L. (1917). Applied Motion Studies: a collection of papers on the efficient method to use industrial preparedeness. Nova lorque: Sturgis \& Walton Company.

GEORGE, C., Jr. (1974). História do pensamento administrativo. São Paulo: Cultrix.

GOODWIN, C. (2005). História da psicologia moderna. São Paulo: Cultrix.

GRAMSCI, A. (2011). O leitor de Gramsci: escritos escolhidos. Carlos Nelson Coutinho (org.) organizador. Rio de Janeiro: Civilização Brasileira.

HALL, S. (1919). The possible war effects on american psychology. Psychological bulletin, Vol. 16, pp. 48-49. 
HOMANS, G. (1967). As pesquisas na Wester Eletric. In: BULÃO, Y. \& CORDEIRO, L (org,). O comportamento humano na empresa. São Paulo: FGV.

HUGHES, J. (1991). Thomas Willis: his life and work. London: Royal Society of Medicine.

MAIER, N. (1966). Psicologia Industrial. Madrid: Ediciones RIALP S.A.

MAYO, E. (1972). Problemas humanos de uma civilización industrial. Buenos Aires: Nueva Visión.

MÜNSTERBERG, H. (1909). Psychology and the Market.McClure's Magazine. Novembro, pp. 87-93. Disponível em: <http://www.unz.org/Pub/McClures-1909nov-00087>. Acesso em: 01/09/2019.

MÜNSTERBERG, H. (1922). Hugo Münsterberg: his life and work. New York: Appleton. Disponível em: <https://archive.org/details/hugomnsterberg00mnuoft>. Acesso em: 28/12/2014.

NUSSBAUM, M; RORTY, A. (1995). Essays on Aristotle's de Anima. Oxford: Clarendon Press.

O'DONNELL, J. (1985). The origins of behaviorism: american psychology. Nova York: New York University Press.

OLIVEIRA, Anamar. (2012). A psicologia de Platão: sobre a teoria da psyché (alma) humana no diálogo Fedro, a partir das categorias do apolíneo e do dionisíaco. Revista Plêthos, 2, 1.

VIEIRA, Rodrigo. (2018). As intervenções teórico-ideológicas da Psicologia Organizacional e do Trabalho nas relações sociais de produção no século XX e início do XXI. Tese de Doutorado. Pós-Graduação em Ciências Sociais da Universidade "Júlio de Mesquita Filho" - Campus de Marília.

RIEBER, R; ROBINSON, D. (2001). Wilhelm Wundt in history: The making of a scientific Psychology. New York: Kluwer \& Plenum.

SEGALL, G. (2001). John D. Rockefeller: Anointed With Oil. Oxford University Press.

SEMERARO, G. (2006). Intelectuais "orgânicos" em tempos de pós-modenidade. In: Cad. Cedes. Campinas, vol. 26, n. 70, p. 373-391, set./dez.

STEVENS, S. (1986). Psychophysics: introduction to its perceptual, neural, and social prospects. New York: Transactions Publishers.

TAYLOR, F. (2012). Princípios da Administração Científica. São Paulo: Atlas.

TRAGTENBERG, M. (2005). Administração, poder e ideologia. São Paulo: Editora Unesp.

TRAGTENBERG, M. (2006). Burocracia e Ideologia. São Paulo: Unesp.

VALLAS, S. (2001). Science, Capitalism, and the Rise of the 'Knowledge Worker': The Changing Structure of Knowledge Production in the United States. Theory and Society, vol. 30, no4, julho de 2001, pp. 451-492. 